\title{
Numerical 3D simulations of seepage and the seepage stability of the right-bank dam of the Dry Flood Control Reservoir in Racibórz
}

https://doi.org/10.2478/sgem-2018-0003

received October 18, 2017; accepted January 12, 2018.

\begin{abstract}
This article presents the results of numerical simulations of seepage through the body of the dam and the reservoir bed. The purpose of this study was to analyse the seepage stability during a flood as well as the impact on seepage stability of the diaphragm wall and gravel columns, on which the dam body is founded in selected segments. Simulations were conducted for three different locations, and the following 3D models of the dam were prepared:

- a model containing the front and right-bank part of the dam, for which no diaphragm wall, gravel columns and drainage ditch were provided for

- a model of a segment of the right-bank dam including a diaphragm wall, drainage ditch and gravel columns under the dam (two variants with differing diaphragm wall lengths)

- a model of the water dam segment accounting for gravel columns and a drainage ditch, but without a diaphragm wall. In the case of founding on gravel columns, the base was modelled as an anisotropic medium in terms of seepage properties, macroscopically equivalent to the actual soil medium.
\end{abstract}

The numerical model utilises the finite element method. The geometry of the dam and geological substrate was defined in the GIS tools in the form of a 3D model of the terrain and geology of the substrate.

\footnotetext{
*Corresponding author: Tomasz Strzelecki, Wroctaw University of Technology. Faculty of Technology and Natural Sciences. Stefana Batorego 9, 59-200 Legnica, E-mail: tomasz@strzelecki.net.pl Anna Uciechowska-Grakowicz, Eugeniusz Sawicki, tukasz Maniecki: Wroctaw University of Technology. Faculty of Civil Engineering. Plac Grunwaldzki 9, 50-377 Wroclaw Michat Strzelecki: KGHM Cuprum Ltd Research and Development Centre, New Energy Technologies Department, ul. Gen. Wt. Sikorskiego 2-8 53-659 Wroctaw
}

Keywords: Seepage; 3D simulation; anisotropy; gravel columns.

\section{Introduction}

To reinforce the substrate, parts of the dam on the Racibórz Dolny reservoir were founded on gravel columns, and other parts on concrete columns (Design of JPP Consult 2015). Over the course of the reservoir's exploitation, the presence of gravel columns will increase seepage, mainly in the vertical direction, which may have an effect on the seepage stability and the head of the groundwater table beyond the reservoir, as well as on the creation of flooding zones. This work analyses the effect of gravel columns and various lengths of the diaphragm wall on the seepage process over the course of the reservoir's exploitation. Computations were conducted using 3D FEA for higher accuracy - differences between results of 2D and 3D modelling of seepage were discussed by Ahmed and Bazaraa (2009) or Jafari et al. (2016).

The work concerns the right-bank and frontal dam of the reservoir. This is a low dam $(<15 \mathrm{~m})$, and it predominantly has a height of approximately 6-8 $\mathrm{m}$, sporadically reaching up to $9 \mathrm{~m}$. Two types of crosssections are present in the analysed area according to the design (Hydroprojekt DHV Group, 2011, 2012): a dam made of loose materials with a diaphragm wall made of cohesive material, and a dam made up of local cohesive materials, utilising flood banks. The exterior dimensions of both types are identical and are as follows:

- crown elevation $197.50 \mathrm{~m}$ above sea level

- $\quad$ grade of waterside slope 1:3

- grade of air-side slope 1:2.5

- crown width $6 \mathrm{~m}$

- width of ledges with technological (service) roads $4 \mathrm{~m}$ 
Over a 532-metre-long segment (from $\mathrm{km} 0+000$ to $\mathrm{km}$ $0+532$ ), the dam has the form of a buttress of the existing railway embankment.

In the construction design, sealing of the dam's substrate was planned in the form of a diaphragm wall made by deep soil mixing technology. This is to be found on the segments: $\mathrm{km} 2+150$ to $4+500, \mathrm{~km} 4+940$ to $5+210$, $\mathrm{km} 6+380$ to $7+490, \mathrm{~km} 7+580$ to $8+300$. Breaks in the diaphragm wall were designed to enable the free flow of water in periods without floods. The problem of these breaks was analysed in the simulation process.

\section{Description of the reservoir}

The Racibórz Dolny reservoir is being built on the Oder River in the Śląskie voivodeship within the territory of four communes: Racibórz, Lubomia, Kornowac and Krzyżanowice, between the road bridge in Krzyżanowice, where it adjoins the Buków polder, and the frontal dam at kilometre 46+300, above the town Racibórz (about 56 thousand inhabitants). According to the design, water will only be impounded in the reservoir during a flood. Environmental costs of the reservoir were investigated for four exploitation variants by Panasiuk (2014).

The Racibórz Dolny reservoir consists of the frontal dam, along with gate-controlled spillway, the left-bank and right-bank dam along with accompanying devices, as well as operational facilities. Gravel mining areas are found within the reservoir's basin (fig. 4). Localization of the reservoir is presented in Fig. 1, a view of the reservoir model is presented in Fig. 2.

Selected parameters of the reservoir are as follows (Hydroprojekt DHV Group, 2011, 2012):

- Top water level $195.20 \mathrm{~m}$ above sea level

- Water volume at top water level approx. 185.0 million m3

- Water surface at top water level approx. $26.3 \mathrm{~km} 2$

- Total length of earth dams approx. $21.8 \mathrm{~km}$

- Maximum height of earth dams $11.1 \mathrm{~m}$

After gravel deposits have been completely exploited, the reservoir's volume is planned to rise to 300 million m3. Analysis of the influence of the volume of the Raciborrz reservoir on flood damage for the Odra Basin was presented by Faganello \& Attewill (2005).

According to the geological documentation (Mineral and Energy Economy Research Institute 2001, GEOSKOP 2014), the soils in the substrate of the right-bank dam are Quaternary (Pleistocene and Holocene) formations,

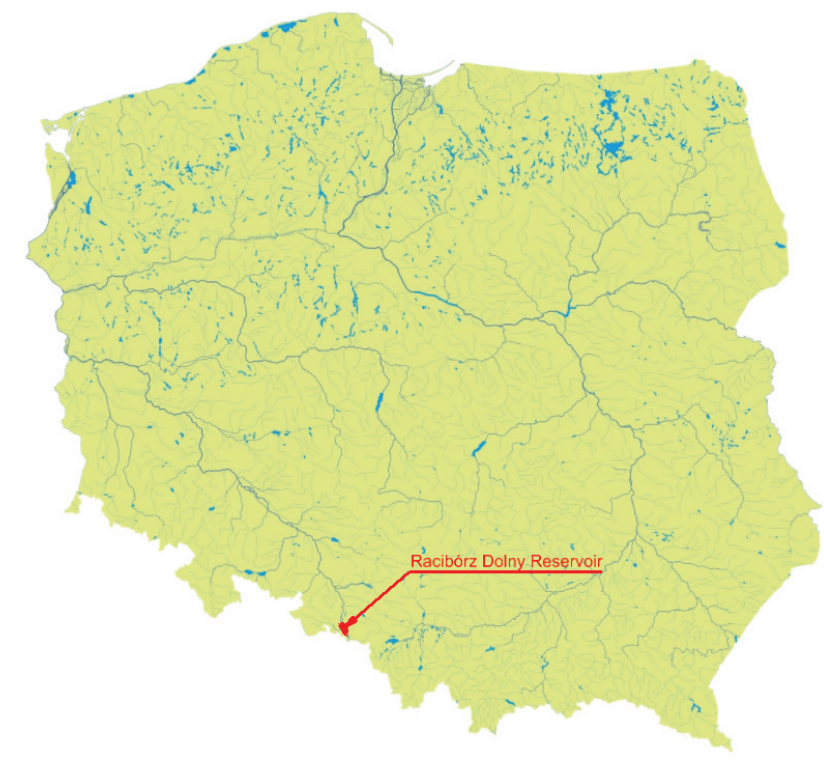

Figure 1: Localization of the reservoir on the hydrographic map of Poland (Aoteroa, 2006).

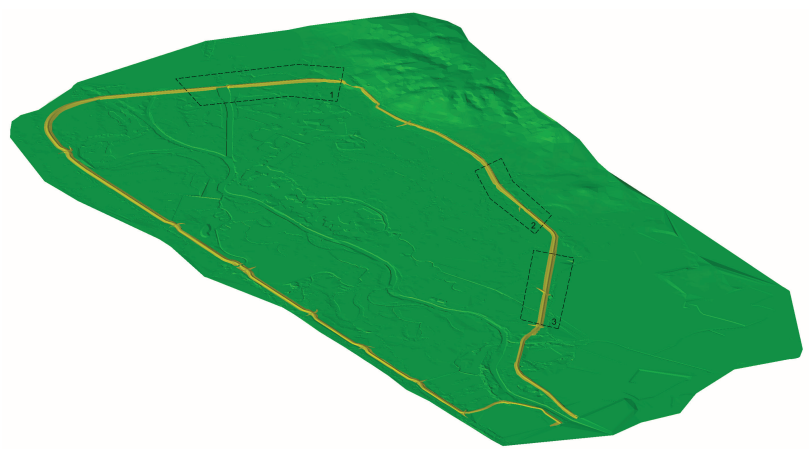

Figure 2: View of the triangle mesh of the terrain model of the reservoir's area, with locations of numerical models

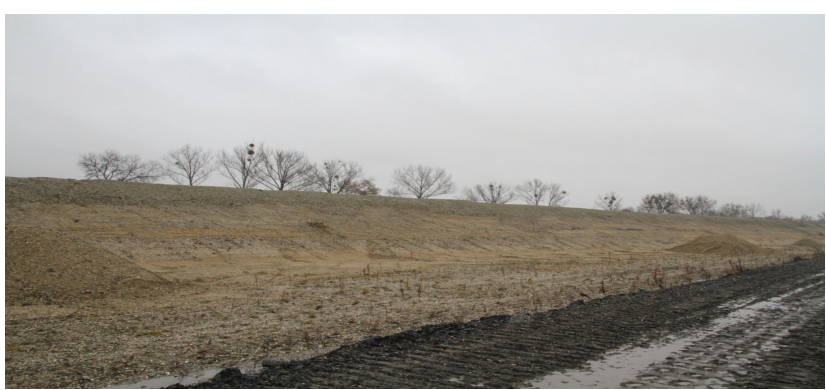

Figure 3: Fragment of the dam built of material from local mines, $\mathrm{km}$ $1+900$.

below which Tertiary formations are found. In the area of the reservoir, the main water-bearing horizon is present in Quaternary sands and gravels, and it has a hydraulic connection with the Oder River. The chemical composition of groundwater was described in detail by Miotliński, 


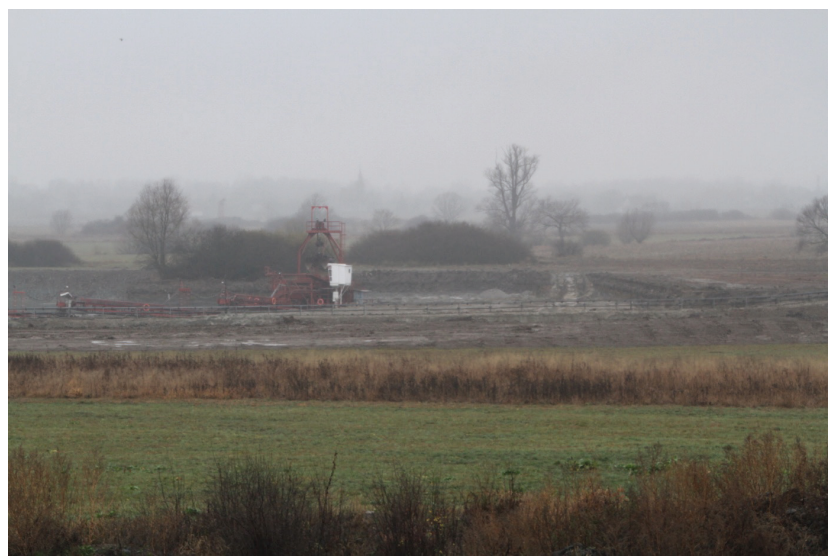

Figure 4: One of gravel mines within the reservoir's basin, view from the right-bank dam, $\mathrm{km} \mathrm{2+400}$.

Postma \& Kowalczyk (2012). These soils are present throughout nearly the entire area of the right-bank dam at a depth of $0.3 \div 8.0 \mathrm{~m}$ below the ground level, and at $\mathrm{km} 1+480$ and $2+280$ of the dam, they are present directly under the soil layer. The overlay and underlay of the aquifer are made up of cohesive Holocene formations. Shallow suspended waters may also occur periodically in the overlay of cohesive soils. The groundwater table stabilised from $185.55 \mathrm{~m}$ above sea level to $191.72 \mathrm{~m}$ above sea level during the period from November 2013 to February 2015, and fluctuations of the GWT amount to approximately $2 \mathrm{~m}$ depending on the intensity and duration of precipitation and the water level in the Oder.

The following values of hydraulic conductivity were accepted for the distinguished geological layers, partially based on our own laboratory tests and on other geological engineering data as well:

- for Quaternary sands and gravels making up the main water-bearing horizon and for the body of the earth dam (Fig. 3) $\mathrm{k}=2.2^{\star} 10-4 \mathrm{~m} / \mathrm{s}$

- for cohesive Holocene formations present in the area of the reservoir $\mathrm{k}=1^{\star} 10-8 \mathrm{~m} / \mathrm{s}$

- for gravel columns on which certain segments of the dam are founded $\mathrm{k}=1^{\star} 10-5 \mathrm{~m} / \mathrm{s}$

- the layer of silts, interpreted as Tertiary and found below the aforementioned formations, was accepted to be non-permeable.

\section{Mathematical model}

A 3D hydraulic model of seepage with a free or constrained water table was applied for simulations. A uniform water density distribution was accepted in the fluid continuity equation, and under this assumption, it has the form given by Strzelecki et al. (2008, 2015):

$$
\operatorname{div}(\vec{v})=-\eta_{s p r} \frac{\partial H}{\partial t},
$$

where $\vec{v}$ is the flow rate vector, $\mathrm{H}$ is hydraulic head, and $\eta_{s p r}$ is the elastic storage coefficient of the aquifer. This is a small quantity, and its value fluctuates within the range of $10^{-6} \div 10^{-5}\left[\mathrm{~m}^{-1}\right]$, and can be determined using the formula:

$$
\eta_{s p r}=\rho g\left(\beta_{s}+f \beta_{w}\right)
$$

$\beta_{s} i \quad \beta_{w}$ are volumetric compressibility of the soil skeleton and water, respectively, $\rho$ is the density of water flowing through the medium, $f$ is the porosity of the soil medium and $\mathrm{g}$ is the earth's gravitational acceleration.

After accounting for the equations of motion for the case of an isotropic medium in the form of:

$$
v_{i}=-k H_{, i},
$$

and defining the piezoconductivity coefficient as:

$$
a=\frac{k}{\eta_{s p r}}=\frac{k}{\rho g\left(\beta_{s}+f \beta_{w}\right)},
$$

the continuity equation can be presented in the following form:

$$
\nabla^{2} H=\frac{1}{a} \frac{\partial H}{\partial t}
$$

This is the differential equation of transient seepage in a homogeneous and isotropic medium in an elastic flow regime, which has been discussed in many works, including those of Polubarinova-Kochina P. J. (1962) and Wieczysty A. (1982). This model is widely used in the example by Strzelecki (2014) for modelling of airport drainage system, also as its simplified 2D version, by Moharrami et al. (2015) for finding optimal geometry of cut off walls or Khalili Shayan \& Amiri-Tokaldany (2015) for investigating the effectiveness of methods of reducing seepage and uplift pressure.

\section{Numerical model}

Due to the fact that the finite element mesh would number many millions of elements in a model of the entire reservoir 
area and that there would be large disproportions of the dam's dimensions relative to the entire area, which could significantly affect the accuracy of numerical simulations, 3 separate numerical models of a smaller area were created to investigate the impact of the geometry of diaphragm wall on the seepage stability. It was recognised that the following models would be necessary to draw conclusions as to the role of gravel columns and the length of the diaphragm wall in the dam's structure:

- a model containing part of the frontal dam and rightbank dam, for which no diaphragm wall, gravel columns and drainage ditch were provided for

- a model of the segment of the right-bank dam containing a diaphragm wall, drainage ditch and gravel columns under the dam

- a model of the dam segment including gravel columns and a drainage ditch, but without a diaphragm wall.

The following assumptions were made when building the 3D seepage model:

- The geometry of the substrate for each of the three considered cases was introduced on the basis of a grid with a $3 \mathrm{~m} \times 3 \mathrm{~m}$ mesh, which makes it possible to unambiguously define the shape of the dam.

- The thickness of the diaphragm wall was enlarged to $3 \mathrm{~m}$ due to the limitations of the numerical model, which, in our opinion, is not of great significance from the perspective of end results.

- It was assumed that air-side horizontal drainage comes into contact with the drainage ditch.

- Moreover, it was assumed that the drainage ditch is in direct contact with the layer of gravels underneath the ditch.

The following boundary and initial conditions are present in the model:

- Dirichlet condition in the form of: $H=H_{b}$, defining a known hydraulic head at points on the bank with coordinates $(\mathrm{x}, \mathrm{y}, \mathrm{z})$

- Neumann condition on non-permeable boundary:

$$
\frac{\partial H}{\partial n}=0 \text {, }
$$

where $n$ - normal to the bank

- mixed condition:

$$
\frac{\partial H}{\partial n}=a^{*} f(H)
$$

defining a known flow through a surface and used on the ground surface in this work in order to determine the influence of infiltration on groundwater level
- An initial condition was accepted that the water table was inclined along a plane parallel to the slope of individual layers at the heights determined by geological tests.

- The maximum water level elevation in the reservoir was accepted to be $196 \mathrm{~m}$ above sea level. A time until the start of raising of the water table equal to 2 days was accepted in the scenario.

- The time for which a constant water level is maintained is equal to 25 days.

\section{Averaging of parameters for the area where gravel columns are present}

In the case of water flow through a clayey soil layer in which a condensed grid of gravel columns was placed, according to homogenization theory (Strzelecki et al. 1996, Auriault 1991), an anisotropic soil medium in terms of seepage properties was introduced, constituting the macroscopic equivalent of the actual soil medium. The representative VER element accepted by us is a cuboid prism with base dimensions of $12 \mathrm{~m} * 12 \mathrm{~m}$ and a height of $4 \mathrm{~m}$. The VER accepted for simulations contains 25 gravel columns with a length of $4 \mathrm{~m}$, and it has been presented in Fig. 5 along with generated finite elements. For clayey soil, a hydraulic conductivity equal to $k=10^{-8} \mathrm{~m} / \mathrm{s}$ was accepted in simulations, and for gravel columns, $k=10^{-3} \mathrm{~m} / \mathrm{s}$.

Flow in the direction of the $\mathrm{x}$ axis under the action of a hydraulic head difference $\mathrm{H}$ equal to $12 \mathrm{~m}$ was accepted for calculations of the hydraulic conductivity in horizontal directions, and flow in the direction of the $\mathrm{z}$ axis under the action of a hydraulic head difference $\mathrm{H}$ equal to $4 \mathrm{~m}$ was accepted in the vertical direction, which gives a hydraulic gradient equal to 1 in both cases. The average value of the hydraulic conductivity was obtained after determining the flow through the water discharge surface from REV by the integration method and dividing this flow by the surface area equal to discharge $(24 \times 4 \mathrm{~m}$ for the horizontal direction and $24 \times 24 \mathrm{~m}$ for the vertical direction). The average value of the hydraulic conductivity in the horizontal direction $k_{x s r}=2 * 10^{-8} \frac{m}{s}$ and in the vertical direction $k_{z s r}=$ üüü $\quad{ }^{-4} \frac{m}{s}$ was obtained. In the further part of this work, the areas in which gravel columns are present will be considered to be anisotropic. 


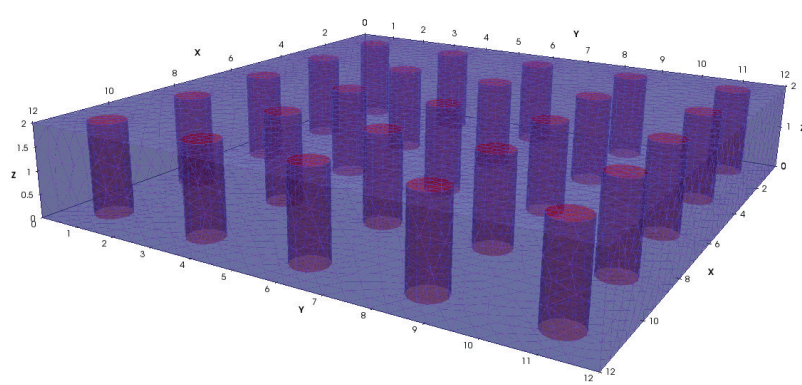

Figure 5: 3D view of the REV element along with the generated finite element mesh

\section{Results of simulations}

\subsection{Results for the part of the dam where no diaphragm wall or drainage ditch were planned}

The reach of the first area analysed around the part of the dam was defined with consideration of the bed of the tributary of the Oder River under construction and the bank of the water reservoir on the dam's air-side. 2 gravel mines on the water-side of the dam were also taken into account. The geometry was made up of 5 layers. The mesh contains 166,460 nodes and 112,284 tetrahedral finite elements. The geometry of the area and the generated finite element mesh in exaggerated scale with 5:1 overscale is presented in Fig. 6 .

The evolution of changes in hydraulic head $\mathrm{H}$ at the level of the gravel layer below the clay layer is presented in fig. 7. The elevation of $196 \mathrm{~m}$ above sea level is $0.8 \mathrm{~m}$ higher than the accepted maximum elevation in the technical design, which additionally creates an unfavourable situation from the perspective of the process under analysis.

A chart of hydraulic head in a selected cross-section after identical time periods is presented in Fig. 8.

In order to illustrate seepage, Fig. 9 presents the vector field of seepage rate in the gravel layer underneath the clay layer for the same time periods as in the charts above.

As predicted, both the created riverbed and the water reservoir drain groundwaters during the period of the regular groundwater regime before and during a flood. During a flood, the effect of river and reservoir drainage can clearly be seen on the air side. Seepage rate values fall within the range from 0 to $2 * 10^{-4} \mathrm{~m} / \mathrm{s}$ in comparison to the range from 0 to üüü ${ }^{-6} m s$ before a flood. Therefore, there is a significant increase in seepage speed in the initial phase of water table rise on the air-side by nearly

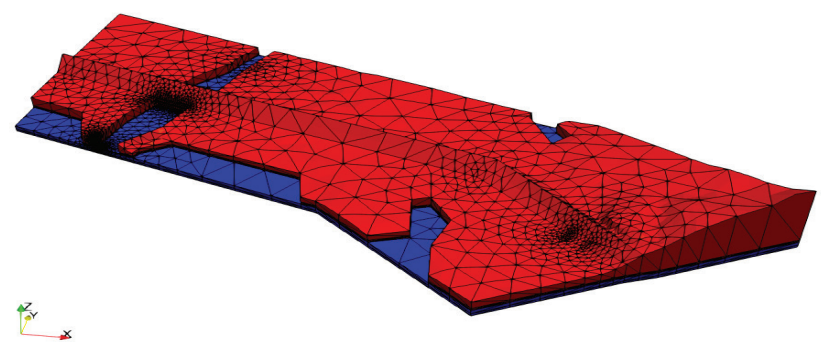

Figure 6: Generated 3D finite element mesh for Dam 1.

two orders of magnitude. Further on, in the process of reservoir filling, seepage rates decrease somewhat but are greater than rates before the flood. After a flood, seepage rates are similar to those obtained before the flood. Gravel mines have an impact on the water seepage process. Direct contact of water in the reservoir with gravel layers causes the gravel layer to perform the role of horizontal drainage, which drains water from the reservoir into the river and water reservoir.

Calculations of the potential of gravimetric seepage forces divided by the vertical component of the seepage rate vector were carried out for each part of the dam:

$$
\Psi=\gamma_{w} \frac{\partial H}{\partial z}+\gamma_{o g},
$$

where $\gamma_{w}$ is the specific weight of water, and $\gamma_{o g}$ is the bulk weight of soil. Fig. 10 given below presents the value of potential $\Psi$ on the surface of the terrain and in one of the cross-sections.

Potential $\Psi$ changes its sign to negative at several locations near the dam, which indicates loss of seepage stability. However, this zone is small and only occurs in the gravel layer.

\subsection{Simulations for the part of the dam with a diaphragm wall, drainage ditch and gravel columns under the dam}

The geometry of the next part that was analysed was made up of 5 layers. It has been presented in an exaggerated scale with an overscale of 5:1 in Fig. 11. The mesh contains 201,599 nodes as well as 134,099 tetrahedral finite elements

The simulation concerning Dam 2 was conducted in 2 variants of diaphragm wall depth:

- lesser depth when the bottom elevation is found at $177 \mathrm{~m}$ above sea level

- greater depth when the bottom elevation is found at $174.5 \mathrm{~m}$ above sea level 
a)

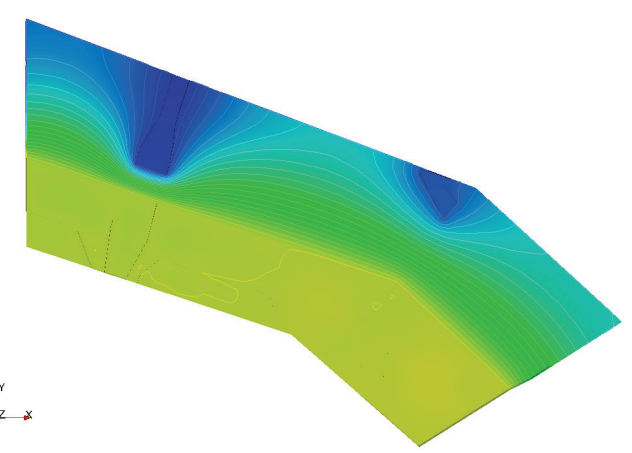

c)

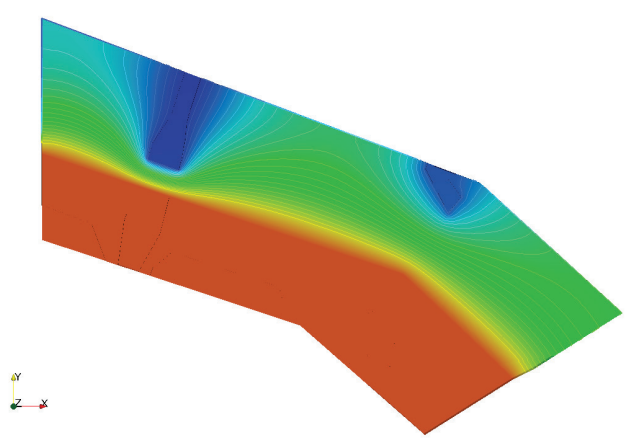

b)

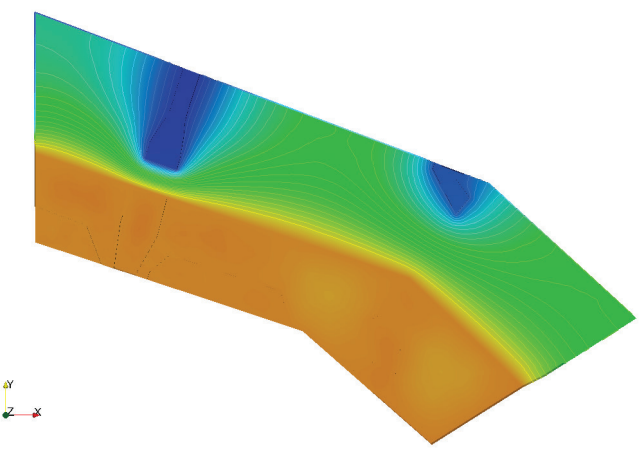

d)

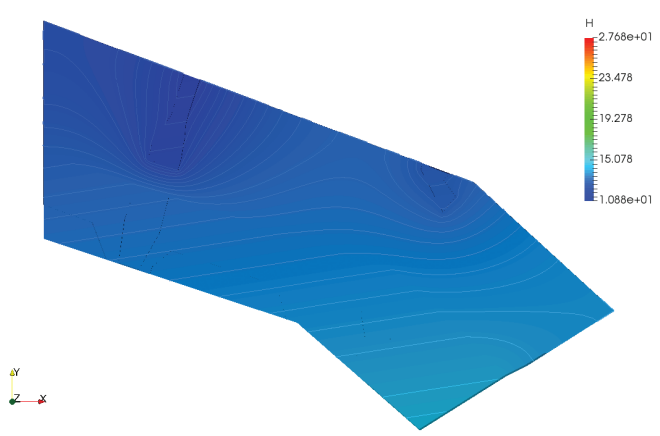

Figure 7: Isolines of hydraulic head relative to the roof of the gravel layer after: a) 1 day, b) 2.5 days, c) 15 days, d) 1 year.

a)

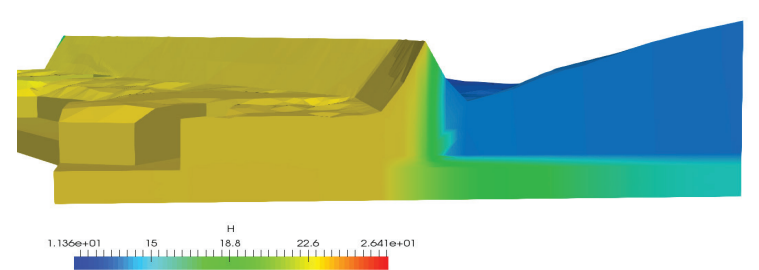

c)

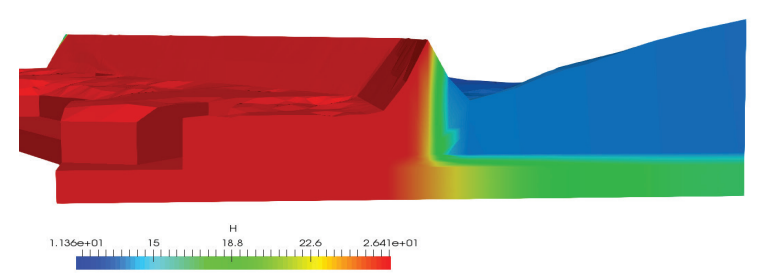

b)

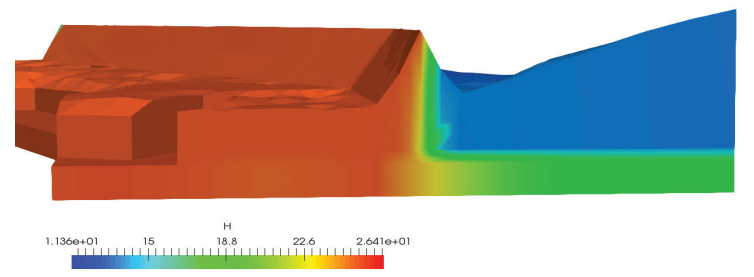

d)

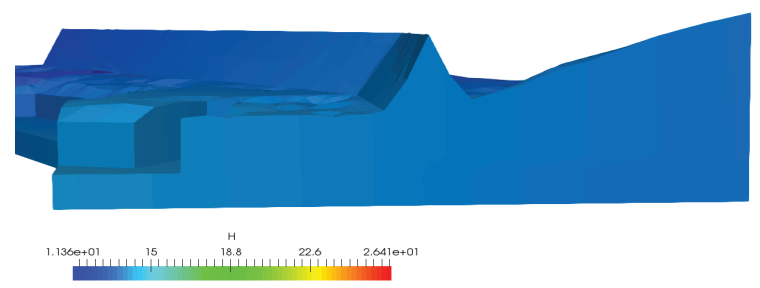

Figure 8: Isolines of hydraulic head in a selected cross-section relative to the elevation of $170 \mathrm{~m}$ above sea level after: b) 1 day, b) 2.5 days, d) 15 days, e) 1 year 
a)

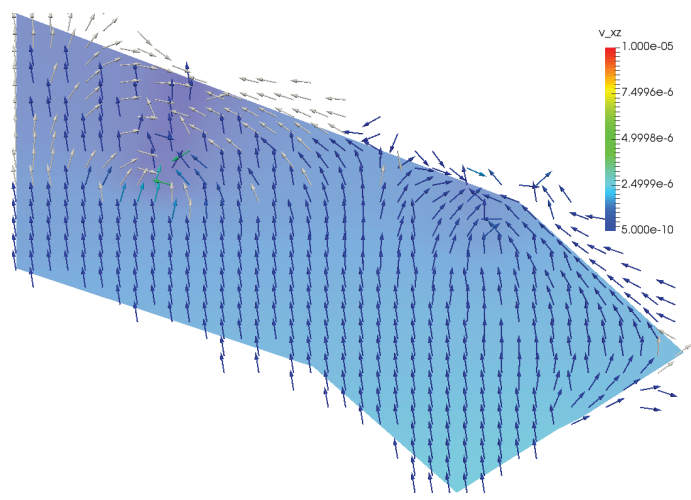

b)

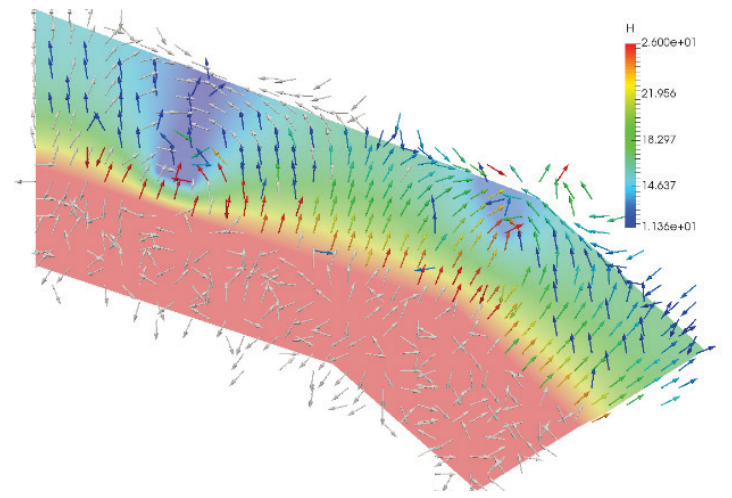

Figure 9: Vector field of seepage speed in the roof of the gravel layer underneath the clay layer after: a) during the period between floods (1 year after flood), b) 15th day of filling. Water table height in gravel layer is shown in the background.

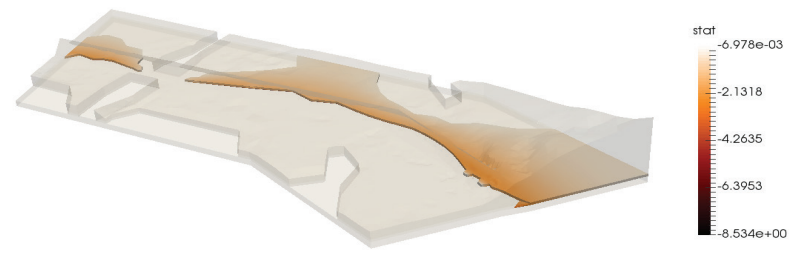

Figure 10: Area of change of potential $\Psi$ to a negative sign on the 15th day of reservoir filling.

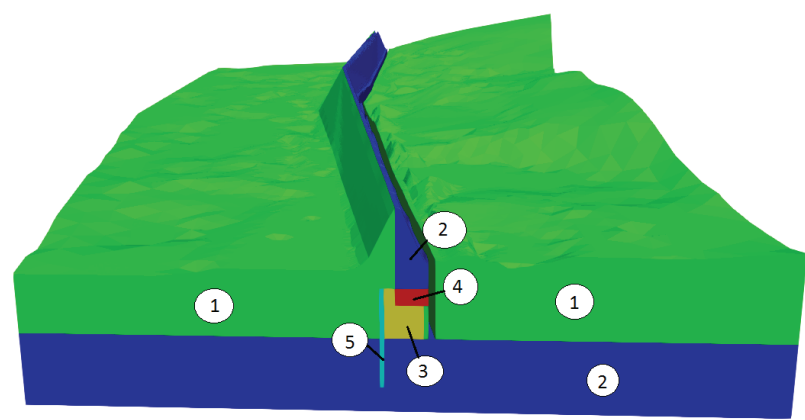

Figure 11: Model geometry (10x exaggeration): 1. clay, 2. gravel, 3. gravel columns in clay, 4. drain, 5. Diaphragm wall

In the case of a shorter diaphragm wall, during the period before a flood, the value of seepage rate is within the range from 0 to $9,16 * 10^{-7} \mathrm{~m} / \mathrm{s}$. During a flood, the seepage rate values range from 0 to $6.57 * 10^{-6} \mathrm{~m} / \mathrm{s}$. Therefore, there is a significant increase in seepage rate in the initial phase of water table rise on the air side by nearly one order of magnitude. Further on, in the process of reservoir filling, seepage rates decrease somewhat but are greater than rates before the flood. After a flood, seepage rates are similar to those obtained before the flood. In the case
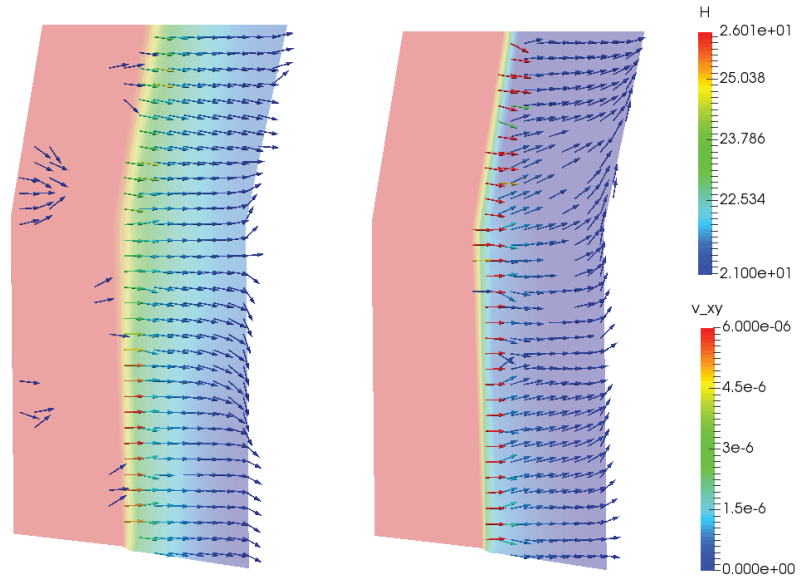

Figure 12: Seepage rate vectors on the 15th day of a flood, in the gravel layer for the case of the shorter diaphragm wall (left) and longer diaphragm wall (right).

of application of a longer diaphragm wall, during the period before a flood, the value of seepage rate ranges from 0 to $8.35 * 10^{-6} \mathrm{~m} / \mathrm{s}$, and during a flood from 0 to $4,81 * 10^{-5} \mathrm{~m} / \mathrm{s}$ (Fig. 12).

Due to an elevated seepage rate, potential flooding zones are decidedly larger in the case of the shorter diaphragm wall. Figure 13 presents a comparison of water table height in the case of no drainage for both variants.

For the discussed part of the dam, in the case of the shorter diaphragm wall, similar to the previous segment, potential $\Psi$ changes to a negative sign at several locations near the dam, which indicates loss of seepage stability. After a certain time, a plus sign appears again at these locations, so the danger passes over time. The area of potential risk in the cross-section is small and occurs near the ground's surface during a flood near the point of 

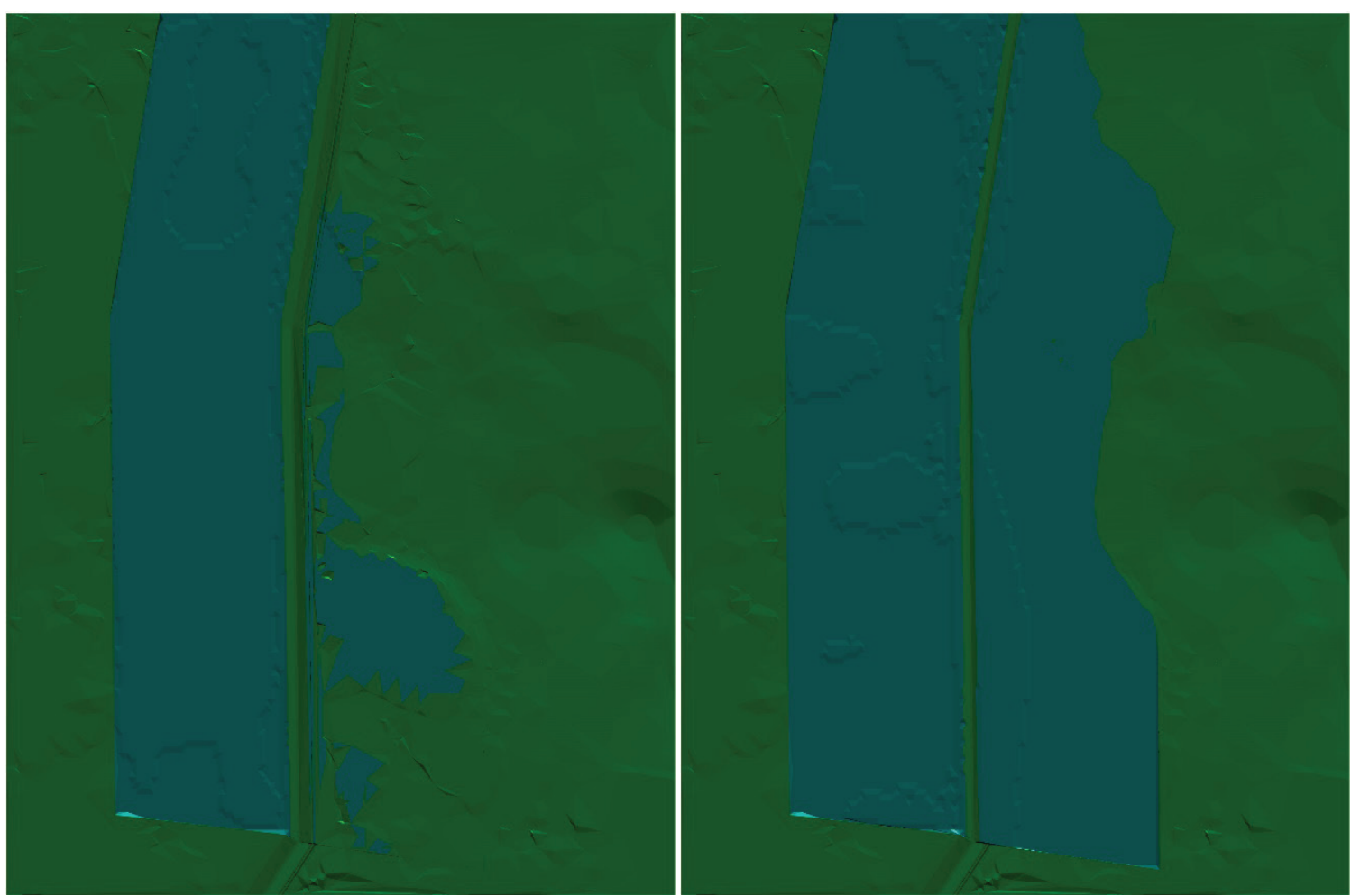

Figure 13: Comparison of water table height (in the case of no drainage) for both variants of diaphragm wall length. Longer diaphragm wall on the left, shorter on the right 6.3

a)

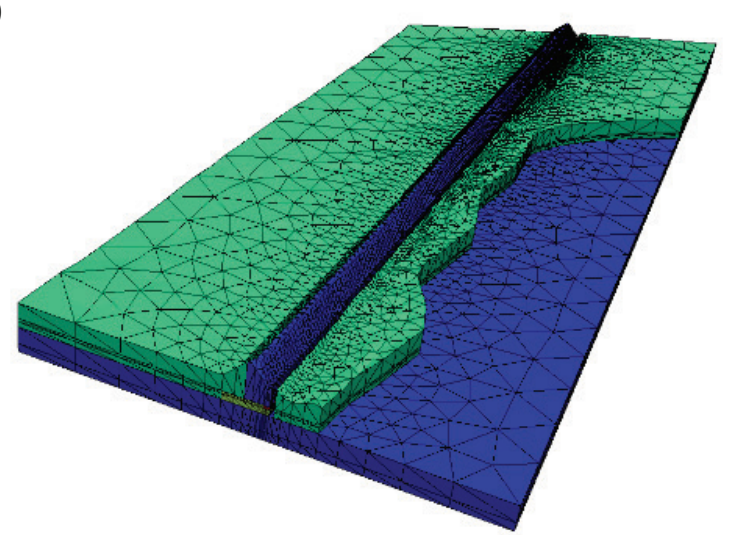

b)

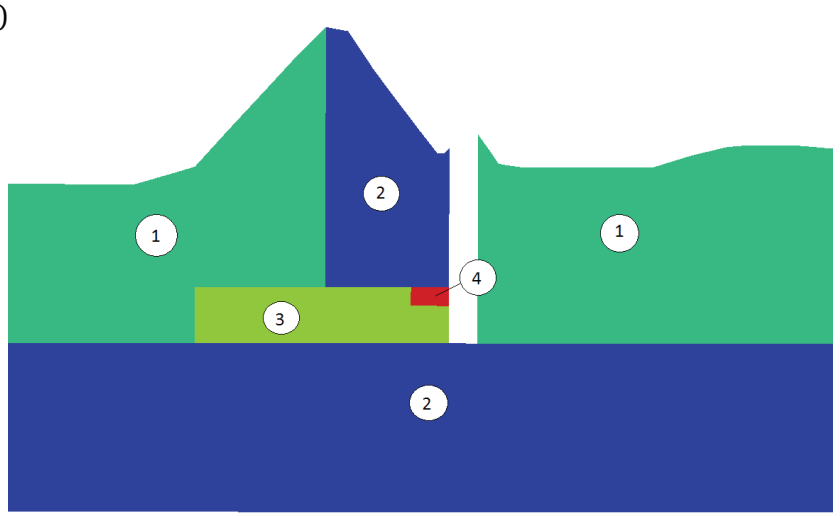

Figure 14: A) Generated 3D finite element mesh B) Cross-section through dam 3: 1. clay, 2. gravel, 3. gravel columns in clay, 4. drain

contact between the dam's slope and native soil on the air side. In the case of application of the longer diaphragm wall, the potential does not change signs, thus there is no risk of losing seepage stability.

Results of simulations of the part of the dam founded on gravel columns, with a drainage ditch, but without a diaphragm wall.

The part of the dam on its air-side is within the reach of the next modelled area. A grid with a $3 \mathrm{~m}$ square mesh was made as the numerical terrain model. The modelled area consists of 5 layers. The geometry of the area along with the generated finite element mesh, in a contaminated scale with an overscale of 5:1, as well as an example cross-section, are presented in Fig. 14. The mesh contains 132,939 nodes and 89,741 tetrahedral finite elements.

The evolution of changes of hydraulic head $\mathrm{H}$ at the level of the gravel layer underneath the clay layer is presented in Fig. 15.

During the period before a flood, the value of seepage rate ranges from 0 to $4,99 * 10^{-6} \mathrm{~m} / \mathrm{s}$. During a flood, the 
a)

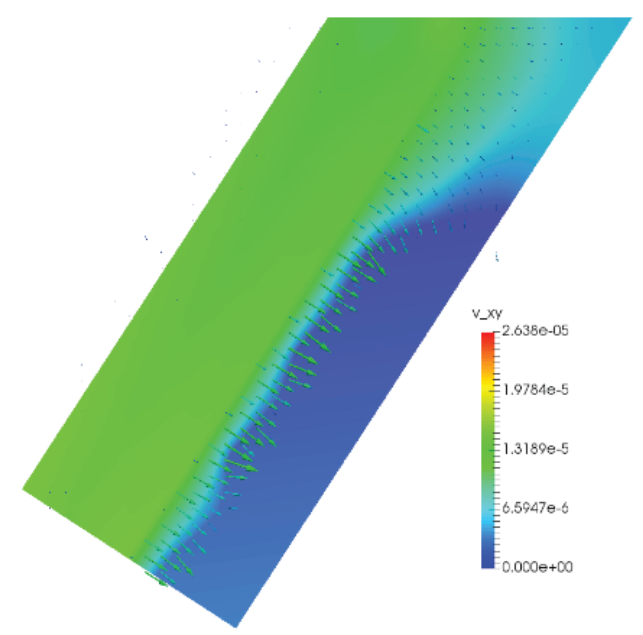

b)

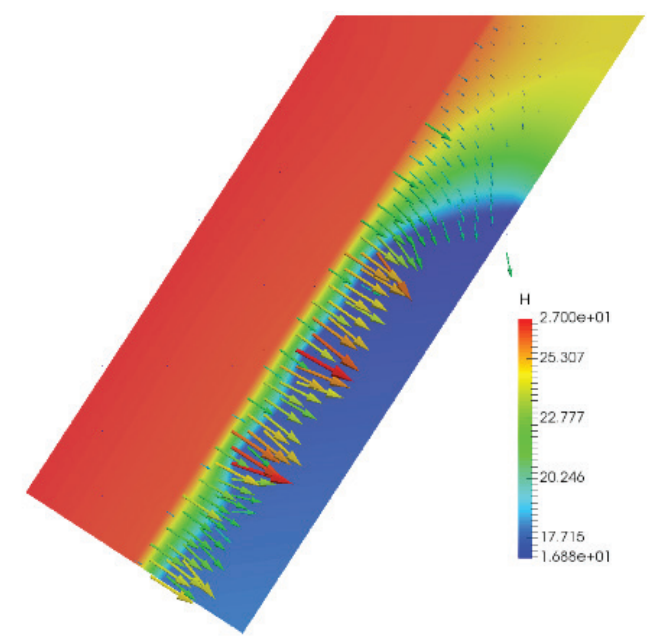

Figure 15: Isolines of hydraulic head and flow vectors in the gravel layer at $170 \mathrm{~m}$ above sea level after: a) 1 day, b) 15 days.

value of seepage rate ranges from 0 to $2,15 * 10^{-5} \mathrm{~m} / \mathrm{s}$. Later, during the reservoir filling process, flow rates decrease slightly, however, they are still greater than the rates from before the flood. After a flood, flow rates are similar to those obtained before the flood.

In the analysed part, potential $\Psi$ is always positive, so there is no loss of seepage stability.

\section{Summary}

The research conducted and discussed was intended to illustrate the following in a 3D numerical model:

- the effect of the designed diaphragm wall on the seepage process

- the leaving of so-called windows, or segments of the right-bank dam without any diaphragm wall

- the effect of gravel columns on the water seepage process

- the effect of a drainage ditch on the seepage process

Three separate numerical models concerning three locations of the right-bank dam were made. In the case of the part of the dam with a diaphragm wall, two cases with different diaphragm wall depths were analysed: depths of $10 \mathrm{~m}$ and 12.5 , in order to analyse the impact of diaphragm wall length on results of numerical simulations obtained from the model.

Conducted simulations made it possible to draw the following conclusions:
1. Gravel columns in the clay layer have a decidedly unfavourable effect on the values of the obtained flows of water discharged on the air side, which affected the size of the flooded zones. However, considering that water pumps will be installed on the air side near the dam to pump excess water into the reservoir, such zones may not occur at all - greater pump output will be required for a shorter diaphragm wall.

2. The designed diaphragm wall should have a length of at least $12.5 \mathrm{~m}$. As shown by the conducted analyses, flooded zones are significantly reduced as diaphragm wall length increases.

3. The concept of leaving breaks in the diaphragm wall is unjustified in our opinion. A significantly greater number of pumps would have to be installed in the area of 'windows' in order to reduce the flooded zone on the air side.

4. The results of simulations of loss of seepage stability indicate that, locally, on the segment of the frontal dam, areas with a significantly reduced stability coefficient are present on the air side. Therefore, this confirms the need to perform works intended to reinforce the soil in this part of the dam.

\section{References}

[1] Ahmed, A.A. \& Bazaraa, A.S. (2009). Three-dimensional analysis of seepage below and around hydraulic structures. Journal of Hydrologic Engineering 14(3). 
[2] Aotearoa (draftsman). (2006). Hydrographic map of Poland, Retrieved from Wikimedia Commons website: https:// commons.wikimedia.org/wiki/File:Polska_hydrografia2.jpg.

[3] Auriault, J.L. (1991). Heterogeneous medium, is an equivalent macroscopic description possible? International Journal of Engineering Science 29( 7): 785-795.

[4] Faganello E. \& Attewill L. (2005). Flood Management Strategy for the Upper and Middle Odra River Basin: Feasibility Study of Racibórz Reservoir, Natural Hazards 36:273-295.

[5] GEOSKOP Sp. z o. o., Sp. k. (2014). Sprawozdanie z badań Geotechnicznych (Report on geotechnical surveys) [In Polish].

[6] Hydroprojekt DHV Group. (2011). Operat Wodnoprawny Zbiornik przeciwpowodziowy Racibórz Dolny na rzece Odrze w województwie śląskim (polder) (Report on water and law matters - Flood Control Reservoir Racibórz Dolny on the Odra River in Śląskie Voivodship (Polder)) [In Polish].

[7] Hydroprojekt DHV Group. (2012). Projekt Budowlany Zbiornika Przeciwpowodziowego Racibórz Dolny na Rzece Odrze w Województwie Śląskim (Polder) (Construction design of Flood Control Reservoir Racibórz Dolny on the Odra River in Śląskie Voivodship (Polder)) [In Polish].

[8] Mineral and Energy Economy Research Institute, Polish Academy of Sciences. (2001). Dokumentacja geologicznoinżynierska dla projektowanego zbiornika wodnego Racibórz Dolny (Geology Engineering Report for designed Reservoir Racibórz Dolny) [In Polish].

[9] Jafari, N.H., Stark, T.D., Leopold, A.L. \& Merry, S.M. (2016). Three-dimensional levee and floodwall underseepage, Canadian Geotechnical Journal 53(1): 72-84.

[10] JPP Consult. (2015). Executive Project - Structure 311, Soil stabilization of right-bank dam in $\mathrm{km} 2+900-3+500,4+000$ 4+400, 4+600-4+850, 5+225-5+650 i 5+800-6+025. [In Polish].

[11] Khalili Shayan, H. \& Amiri-Tokaldany, E. (2015). Effects of blanket, drains, and cutoff wall on reducing uplift pressure, seepage, and exit gradient under hydraulic structures, International Journal of Civil Engineering 13(4).
[12] Miotliński, K., Postma, D. \& Kowalczyk, A. (2012). Variable infiltration and river flooding resulting in changing groundwater quality - A case study from Central Europe, Journal of Hydrology, Vol. 414-415, Pages 211-219.

[13] Moharrami, A., Moradi, G., Bonab, M.H., Katebi, J. \& Moharrami, G. (2015). Performance of Cutoff Walls Under Hydraulic Structures Against Uplift Pressure and Piping Phenomenon, Geotechnical and Geological Engineering 33: 95-103.

[14] Panasiuk, D. (2014). Environmental costs for exploitation variants of Racibórz dry polder, Economics and Environment, 4/2014 146-153.

[15] Polubarinova-Kochina, P. Ya. (1962). Theory of ground water movement. Princeton, NJ: Princeton University Press.

[16] Strzelecki, M. (2014). Numerical Three-Dimensional Model of airport terminal drainage system, Studia Geotechnica et Mechanica 26(1): 111-119.

[17] Strzelecki, T. (red.), Kostecki, S. \& Żak, S. (2008). Modelowanie przepływów przez ośrodki porowate (Modelling of flows through porous media), DWE, Wrocław. [In Polish].

[18] Strzelecki, T. \& Strzelecki, M. (2015). Relation Between Filtration and Soil Consolidation Theories, Studia Geotechnica et Mechanica, 37(1).

[19] Strzelecki, T. (red.), Auriault J.L., Bauer J., Kostecki S. \& Puła W. (1996). Mechanika ośrodków niejednorodnych. Teoria homogenizacji (Mechanics of heterogeneous media. Homogenization theory) DWE, Wrocław [In Polish].

[20] Wieczysty, A. (1982). Hydrogeologia inżynierska (Engineering hydrogeology), PWN, Warszawa [In Polish]. 